effects of others on one individual's number of offspring simply added up. What if interactions combine synergistically, as Queller calls it? The problem here is one of measurement. The third, synergistic. term in Queller's form can be made to disappear by agreeing to define benefit and cost as the average effects on individual's fitnesses. rather than as arbitrary terms in a model of fitness:

So in Queller's simple model. Hamilton's rule. with costs and benefits correctly understood. is perfectly adequate for deciding the direction of change in gene frequency. In more complex models. in which individuals can pay costs and receive benefit many times in a lifetime. a real problem of non-additivity can arise But one way round this is to make the plausible assumption that the gene effects in question are small: Fisher's microscope argument ${ }^{+}$- that near to a good design only small changes are likely to be advantageous - suggests that. in the final stages of the perfection of a character, only genes of small effect matter.

Thus, for genes of small effect, additivity is restored and the correctness of Hamilton's rule is restored with it ${ }^{3}$. (Population geneticists may be interested in genes of large effect. and it is perfectly reasonable to doubt if characters are anywhere near perfection. so not everyone will be happy with this assumption. Note that a gene can have a small effect through rarity of expression even if it has a large effect on the occasions it is expressed.)

The method used by Queller is Price's covariance selection mathematics, a powerful technique of general value ${ }^{3}$ that was originated and expounded by Price in brief articles ". For Queller, the value of the technique was that it enabled him to change easily from counting genes in offspring according to the individual producing the offspring (the usual population genetics method of accounting by results). to counting according to the individual whose genotype caused the existence of the offspring (the inclusive fitness method of accounting by control).

In closing. I must mention a paper unjustly neglected by Queller, in which Price's method was first applied to inclusive fitness problems. This remains the most general and satisfying derivation and justification of inclusive fitness. at the same time as being remarkably simple. Queller cannot appeal to the obscurity of the journal in which the paper appeared. but he can plead for clemency on the grounds that its author himself later neglected the existence of his own strong and powerful result. Readers may have guessed that the author in question is W.D. Hamilton ". His hitherto unsung primacy in providing a simple and rigorous justification for inclusive fitness. together with his well-recognized provision of the idea in the first place. inspire me to end close to where I began: Hamilton rules OK!

1. Hamillon. W.D.J. theor. Birl. 7. 1 (1964)

Oueller. D.C. Nature 318. 36(x) (1985).

Grafen. A Oeford Surveys in Evolutiomary Biology 2. 28 (1985).

Fisher. R.A. The Genctical Theory of Natural Selection (Dover Publications. New York. 1985).

Price. G. R. Nature 227. 520 (197()).

6. Price. G.R. Anm hum. Gienct 35. $485(1972)$

7. Hamilson. W.D. Natura 228. $121 \times(1970)$.

8. Michodt. R.E. \& Hamilton W.D. Nature 288. 694 (1980)

Alan Grafen is a Royal Society 1983 University Research Fellow at the Zoology Department. Oxford University, Oxford OXI $3 P S, U K$

\title{
Developmental biology
}

\section{A reversible epithelium}

\section{from Jared $M$. Diamond}

EPITHEl.ia are the sheets of cells that line body cavities such as the intestinal lumen. They are responsible for active transport of specific solutes, either from lumen to blood or vice versa depending on the particular solute and epithelium. In most cases the direction of transport is fixed, even though the rate of transport may be subject to physiological regulation. On page 368 of this issue G.J. Schwartz, J. Barasch and Q. Al-Awqati describe an unusual case of a reversible epithelium, which can transport the same solute in either direction in response to physiological need. The whole arrangement of pumps, exchangers and vesicles within the epithelial cell is reversible in detail. The tissue not only is a curious violation of the usual rules but also offers a promising system for learning how epithelia become programmed during development.

Schwartz et al. have studied the inter- calated cells of the cortical collecting tubule (CCT) in the kidney. These regulate blood $p \mathrm{H}$ by either secreting $\mathrm{H}^{+}$and absorbing $\mathrm{HCO}_{3}$, or secreting $\mathrm{HCO}$, and absorbing $\mathrm{H}^{+}$. The main physiological stimulus converting the tubule from net $\mathrm{HCO}_{3}{ }^{-}$secretion to net $\mathrm{H}^{\prime}$ secretion is the acid load. Schwartz et al. identify $\mathrm{H}^{+}$secreting or $\mathrm{HCO}_{3}$-secreting cells by the endocytosis of fluorescent markers from the luminal or blood surface of the tubule. respectively. Since epithelial cells are commonly found to transport a given solute in a fixed direction, one might expect the $C C^{\prime} T$ to contain two $\mathrm{H}^{*} / \mathrm{HCO}_{3}$ transporting cell types with opposite functions and the mitotic proliferation (or transport rate) of each cell type to respond to $\mathrm{pH}$ levels. Instead, mitotic figures are absent in intercalated cells of acid-loaded animals and the total number of cells remains virtually unchanged -137 per $\mathrm{mm}$

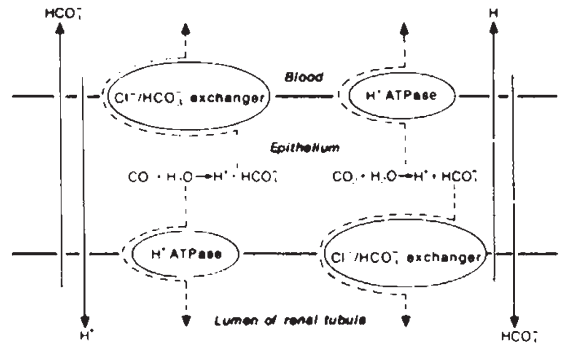

Depending on the respective locations of an ATPase and an exchanger, controlled by the acid load. the intercalated cell of the cortical collecting tubule either secretes $\mathrm{H}^{+}$(left) or $\mathrm{HCO}_{3}$ (right)

of tubule after loading, compared with 129 per $\mathrm{mm}$ before loading. But the number of acid-secreting cells increases 10)-fold. from 7 to 74 , and the number of $\mathrm{HCO}_{3}^{-}$-secreting cells decreases correspondingly, from 122 to 63 . This is evidence for a change in direction of transport in the same cell. rather than proliferation of a cell type with a certain direction of transport.

The change of direction is a result of the simple reversal of the arrangement of the transport mechanism, which consists of a proton-pump ATPase at one cell face and a $\mathrm{Cl} / \mathrm{HCO}$, exchanger at the opposite face (see figure). In $\mathrm{H}^{+}$-secreting cells the ATPase is at the luminal membrane and the exchanger at the blood-facing membrane; these locations are reversed in $\mathrm{HCO}_{3}$-secreting cells. The ATPase originates from intracellular vesicles which fuse with either the luminal or the bloodfacing membrane, so that the ATPase is inserted into the appropriate membrane. Thus, one critical link in the control of transport direction by acid load is control of direction of vesicle movement.

These experiments open the way to exploring other steps in the chain of controls in the CCT. Insertion of the $\mathrm{Cl}^{-} / \mathrm{HCO}_{2}$ exchanger has not been studied and the detailed time course of acid control of ATPase insertion is not yet known. But this study also has broader significance for the developmental biology of epithelia in general. Biologists have long wondered how the genetic information in a radially symmetrical egg becomes translated into radially asymmetrical cells, tissues and animals. In epithelia, this question is posed in a particularly simple form, as functions are segregated between two cell faces. Membrane biologists have learned much about the details of the transport mechanism at each face but have so tar paid little attention to developmental questions of how each mechanism gets inserted into the 'right' end of the cell. Having a cell in which the direction of insertion can be experimentally reversed may make it easier to answer questions such as these.

Jared M. Diamond is Professor of Physiologr at the University of California Medical Schiool Los Angeles, California 90024 . USA. 